57. Singh R. (2009) Company attributes and stock returns in India: A panel data analysis. Journal of Applied Finance, vol. 15, pp. 46-57. Available at: http://crawl.prod.proquest. com.s3.amazonaws.com/fpcache/c76160f03383752cb6028b0a99dfaaa2.pdf?AWSAccessK eyId=AKIAJF7V7KNV2KKY2NUQ\&Expires=1475435112\&Signature=FRGyv1SuN4m NDKLnmoIUWU47yj0\%3D (accessed 30 September 2016).

58. Tong W.H.S. (1992) An analysis of the January effect of the United States, Taiwan and South Korean stock returns. Asia Pacific Journal of Management, vol. 9, no. 2, pp. 189-207. doi:10.1007/BF01732896.

59. Wong K.A. and Lye M.S. (1990) Market values, earnings' yields and stock returnsevidence from Singapore. Journal of Banking and Finance, vol. 14, no. 2-3, pp. 311-326. doi:10.1016/0378-4266(90)90052-4.

60. Wu H. (2010) The Value and Size Effect -Are There Firm-Specific-Pisks in China's Domestic Stock Markets? International Journal of Economics and Finance, vol. 3, no. 3, pp. 26-37. doi:10.5539/ijef.v3n3p26.

61. Zhang X. F. (2006) Information uncertainty and stock returns. Journal of Finance, vol. 61, no. 1, pp. 105-136. doi:10.1111/j.1540-6261.2006.00831.x.

\title{
ДИВИДЕНДНЫЕ ВЫПЛАТЫ РОССИЙСКИХ КОМПАНИЙ В УСЛОВИЯХ ФИНАНСОВОГО КРИЗИСА
}

\section{Анкудинов Андрей Борисович} Лебедев Олег Владимирович²

В работе приведены результаты эмпирического анализа динамики дивидендных выплат отечественных компаний в условиях кредитного сжатия кризисного периода. Анализ основан на панельных данных; выборка сформирована по данным крупнейших российских компаний нефинансового сектора за период 2003-2011 гг. Метод исследования состоял из двух частей: сначала был проведен одномерный анализ зависимости индивидуальных характеристик компаний и проводимой ими дивидендной политики, затем был проведен многовариантный анализ на основе регрессионного оценивания по панельным данным. Полученные оценки показывают, что сформировавшиеся к настоящему времени подходы к распределению прибыли российских компаний таковы, что многие из них не выплачивают дивиденды вовсе (66\% наблюдений относительно долей распределенной на дивиденды прибыли представляют нулевые значения). В среднем доля прибыли, направляемая на дивиденды, составляла 8,5\% (25\% для подвыборки компаний - плательщиков дивидендов), что ниже дивидендного выхода компаний как с развитых, так и со многих развивающихся рынков, и характеризовалась высоким разбросом в пространственном и временном измерении. Четко идентифицируется снижение дивидендов выплат в кризисные годы. В предкризисный период государственные и частные компании характеризовались примерно равной величиной дивидендного выхода, однако в посткризисный период частные компании распределяли на дивиденды большую часть прибыли. Разница в величине выплаченных дивидендов публичных и непубличных компаний в условиях финансового кризиса снижается, однако первые характеризуются существенно более щедрой дивидендной политикой. Ненаблюдаемые индивидуальные характеристики компании оказывают существенное влияние на величину распределяемой на дивиденды прибыли. Прибыльность, размер компании позитивно, а финансовый леверидж негативно коррелированы с вероятностью выплаты каких-либо дивидендов и с величиной выплачиваемых дивидендов. Позитивная зависимость прибыльности и доли прибыли, распределяемой на дивиденды, усиливается в посткризисный период. В то же время негативная

\footnotetext{
${ }^{1}$ Кандидат физико-математических наук, доцент кафедры финансов организации, Казанский федеральный университет, научный сотрудник Университета Иннополис, e-mail: ankudia@mail.ru

${ }^{2}$ Ассистент кафедры финансов организации, Казанский федеральный университет, научный сотрудник Университета Иннополис, e-mail: lebolegan@yandex.ru
} 
зависимость финансового левериджа и дивидендных выплат становится менее выраженной в посткризисный период.

Ключевые слова: дивиденды, дивидендная политика, российские компании, панельные данные, финансовый кризис, государственные компании

JEL: G35, G32

\section{Введение}

Концепция максимизации благосостояния собственников, на основе которой в финансовой теории обосновываются решения в области управления корпоративными финансами, предполагает задействование всех имеющихся рычагов создания стоимости для инвесторов в собственный капитал компании. В условиях же замедления экономического роста в стране, нестабильности на финансовых рынках, внешних шоков от падения цен на основные экспортные товары необходима активизация рыночных инструментов мобилизации финансовых ресурсов резидентов-сберегателей. Формирование последовательной и прозрачной политики в области распределения прибыли может выступить одним из таких инструментов.

Проблема распределения прибыли компании - одна из самых дискуссионных в корпоративных финансах. В научной литературе достаточно широко описаны различные теории оптимальной дивидендной политики (теории иррелевантности дивидендов, налогового предпочтения, предпочтения текущих дивидендов, клиентская теория, сигнальная теория, агентская теория, теория сглаживания дивидендов и др.). В то же время эмпирические свидетельства их тестирования весьма неоднозначны как по развитым, так и по развивающимся рынкам капитала. Многочисленные теоретические разработки и эмпирические исследования не дают однозначных ответов даже о направленности влияния тех или иных решений в плоскости распределения прибыли на акционерную стоимость, не говоря уже об универсальных подходах в политике дивидендных выплат. Более того, рекомендации одних теорий могут быть прямо противоположны другим.

Эмпирические исследования по развитым рынкам капитала демонстрируют, что в условиях финансового кризиса компании, более чувствительные к сжатию возможностей внешнего финансирования, сокращают дивидендный выход в большей степени [Bliss et al., 2014]. Разумно будет предположить, что в условиях трансформационных экономик, где спред между стоимостью финансирования из внутренних и внешних источников значительно больше, этот эффект может проявляться более отчетливо. При этом, если компании на развитых рынках в кризисные годы в целом и сокращают дивидендные выплаты, они делают это неохотно; исследования показывают, что компании зачастую предпочитают сократить капитальный бюджет, чем снизить величину дивидендного выхода [Brav et al., 2005], и даже компании с недостатком ликвидности стараются поддерживать дивидендные выплаты хотя бы на прежнем уровне [Daniel et al., 2008].

Особый интерес вызывает рассмотрение дивидендной политики российских компаний, обусловленной спецификой отечественного рынка капитала, с присущим ему множеством диспропорций [Лебедев, 2015], а также характера видоизменения подходов компаний к распределению прибыли в условиях финансово-экономического кризиса. Таким образом, целью данной работы выступил анализ динамики дивидендных выплат отечественных компаний в условиях кредитного сжатия кризисного периода; при этом мы также оцениваем эффект влияния индивидуальных характеристик компаний на их дивидендную политику в пред- и посткризисный периоды.

\section{Дивидендные выплаты российских компаний}

Эмпирические исследования дивидендной политики отечественных компаний демонстрируют, что дивидендные выплаты российских компаний существенно ниже дивидендного выхода компаний как с развитых, так и развивающихся рынков. И.Т. Кери и др., анализируя данные 50 крупнейших публичных российских компаний за период 2006-2011 гг., показыва- 
ет, что доля чистой прибыли, направляемой компаниями на выплату дивидендов, в среднем составляла около 21\%. [Кери и др., 2011]. Н.К. Пирогов и Н.Н. Волкова, исследуя дивидендную политику компаний таких крупных развивающихся рынков, как Россия, Индия и Китай, в период с 1995-го по 2008 г. (в выборку входят наблюдения по 43 российским компаниям), утверждают, что коэффициент выплаты дивидендов для российских компаний составил около 32\% (при этом коэффициент выплаты дивидендов рассчитывался только для компаний с положительными прибылями) [Пирогов и Волкова, 2009]. Г. Б. Шагалеева анализирует дивидендную политику крупнейших компаний из развивающихся стран (97 российских, 31 польскую и 13 венгерских,) с данными за 2004-2008 гг. Средний коэффициент дивидендных выплат в изучаемых российских компаниях составлял около $16 \%$, в польских $-29 \%$, в венгерских - 15\% [Шагалеева, 2011]. Согласно нашим оценкам на основе анализа выборки по 500 крупным нефинансовым российским компаниям за 2003-2011 гг. (подробнее см. ниже), в среднем доля прибыли, направляемая на дивиденды, составляла 8,5\% (25\% для подвыборки компаний-плательщиков дивидендов). На наш взгляд, разница в цифрах по дивидендному выходу может быть объяснена широтой выборки, поскольку, как правило, крупные компании характеризуются более щедрой дивидендной политикой.

Для сравнения, М. Фасио и др., изучая дивидендную политику компаний из 14 стран Европы и Азии за период 1992-1996 гг., находят, что для европейских стран коэффициент дивидендных выплат был равен 36\%, тогда как для азиатских - 32\% [Faccio et al., 2001]. Р. Бебчук показывает, что величина дивидендного выхода аргентинских компаний за период 1996-2003 гг. была равна 32\% [Bebczuk, 2005]. В целом можно заключить, что уровень дивидендных выплат российских компаний ниже дивидендного выхода компаний как с развитых, так и с многих развивающихся рынков.

Предыдущие эмпирические исследования по дивидендной политике отечественных компаний также указывают на важную роль структуры собственности [Ружанская, Лукьянов, 2010; Шагалеева, 2011] и значительный информационный контент (сигнальные эффекты) объявлений дивидендных выплат [Теплова, 2008; Теплова, 2011]. И.В. Ивашковская и Е.Б. Кукина показывают, что дивидендные выплаты отечественных компаний позитивно ассоциируются с процессом создания стоимости для акционеров (на основе показателя экономической добавленной стоимости) [Ивашковская, Кукина, 2009]. Имеются свидетельства того, что российские компании с кросс-листингом акций с большей вероятностью выплачивают дивиденды, но платят меньшую их величину [Зальцман, 2014]. Хотя на развитых рынках капитала альтернативный инструментарий распределения прибыли через выкуп собственных акций в условиях кризиса демонстрирует большую гибкость [Brav et al., 2005; Leary and Michaely, 2011], на развивающихся рынках чаще практикуется выплата в виде денежных дивидендов, чем в форме выкупа акций [Шагалеева, 2011].

\section{Дивидендные выплаты в условиях кризиса}

Эффект воздействия финансово-экономического кризиса на дивидендные выплаты не столь очевиден, поскольку альтернативные каналы влияния (обсуждаются ниже) не являются взаимоисключающими. Так, если агентские издержки, связанные с необоснованным удержанием прибылей, остаются на прежнем уровне, ожидаемым ответом на кризис и на более высокие издержки внешнего финансирования выступает сокращение дивидендных выплат и удержание большей доли генерируемого денежного потока [Bliss et al., 2014]. Таким образом, подобная политика в некоторой степени может смягчить последствия кредитного шока для компаний, особенно характеризующихся высоким спредом стоимости внутреннего и внешнего финансирования. Кроме того, финансово-экономический кризис ведет к тому, что уровень неопределенности значительно возрастает. Высокая неопределенность повышает ценность формирования финансовых резервов.

В то же время кризис также обусловливает снижение спроса, который может быть вызван снижением благосостояния в целом [Mian and Sufi, 2010]. Подобные шоки сжатия спроса обусловливают сокращение инвестиционных возможностей компаний и, соответственно, 
потребность в финансовых ресурсах. Однако отсутствие привлекательных инвестиционных возможностей может ассоциироваться с более высокими агентскими издержками удержания прибылей.

В научной литературе представлено не так много эмпирических исследований политики выплаты дивидендов в условиях финансово-экономических кризисов. И. Флойд и др., изучая дивидендную политику компаний на развитых рынках за последние 30 лет, находят, что компании реального сектора в условиях кризиса более вероятно сокращают программы выкупа акций, а не величину дивидендного выхода [Floyd et al., 2014]. Также исследователи демонстрируют, что компании часто снижают дивидендные выплаты после кредитного сжатия, поскольку вынуждены обслуживать фиксированные выплаты по облигационным займам [Almeida et al., 2011]. Сокращают величину дивидендного выхода в условиях кризиса прежде всего фирмы, более чувствительные к ограничивающим возможности внешнего финансирования шокам [Bliss et al., 2014].

В целом же исследования по развитым рынкам демонстрируют, что дивидендные выплаты достаточно устойчивы: доля плательщиков и доля распределяемой прибыли если и снижается, то незначительно. При этом финансовые компании менее вероятно по сравнению с компаниями реального сектора сокращают дивидендные выплаты [Floyd et al., 2014]. Одной из основных причин подобного стремления сохранить дивиденды хотя бы на прежнем уровне называется предполагаемая приверженность менеджеров к выплате дивидендов. Поскольку таким образом смягчается проблема агентских издержек, а также сигнализируется уверенность менеджеров в потенциале компании по генерации денежного потока [La Porta et al., 2000; Dittmar et al., 2003].

\section{Гипотеза исследования}

Гипотеза: мы предполагаем, что сокращение дивидендных выплат отечественных компаний в условиях финансового кризиса было неравномерным и в значительной степени детерминировалось характеристиками структуры собственности компании.

Тестируемая гипотеза основывается на теории корпоративного управления А. Шлейфера и Р. Вишны, которые отмечают, что хотя госкомпании и контролируются обществом, они фактически управляются политическими бюрократами, которые имеют в своих руках концентрированные права контроля, тогда как право на денежный поток распылено между множеством акционеров (налогоплательщиков) [Shleifer and Vishny, 1997]. Соответственно, в случае возникновения конфликта интересов между политическими задачами и целью максимизации акционерной стоимости бюрократические интересы берут верх. Собственником-государством компании часто рассматриваются как каналы вливания инвестиций, а не как финансовые активы, от которых частный акционер в свою очередь ожидает максимизации создаваемой стоимости. Мы можем ожидать, что государственные компании имеют меньшее предпочтение дивидендов и склонны удерживать большую часть генерируемого дохода. Обострение подобной ситуации может наблюдаться в условиях финансово-экономического кризиса, поскольку интересы стейкхолдера «государство», обеспокоенного поддержанием социальной стабильности, в российских политических условиях, несомненно, доминируют. Кроме того, следует учитывать и обострение агентских конфликтов в подобных условиях: у менеджмента достаточно «оснований» сократить дивидендные выплаты. Впрочем, возможны и позитивные эффекты наличия государства в виде собственника, например, через установление минимальных требований по дивидендному выходу [Шагалеева, 2011]. Впрочем, насколько известно авторам настоящей работы, гипотеза в представленном виде ранее не тестировалась. При этом имеется ряд эмпирических доказательств того, что дивидендные выплаты госкомпаний действительно резко увеличиваются после приватизации [Boubakri and Cosset, 1998; D’Souza et al., 2000] и что структура собственности оказывает влияние на формирование акционерной стоимости на российском рынке капитала [Анкудинов и Лебедев, 2014].

Также предполагается, что статус публичности и наличие иностранного акционера в структуре собственности позитивно воздействуют на уровень дивидендных выплат в силу как 
доступности финансирования, так и потенциального принуждения менеджмента к цивилизованным формам корпоративного управления и использования финансовой политики в качестве инструмента дисциплинирования менеджмента [Khan, 2006]. По развивающимся рынкам имеются свидетельства позитивной зависимости между дивидендными выплатами и качеством корпоративного управления [Kowalewski et al., 2008; Sawicki, 2009]. Кроме того, эмпирические исследования показывают, что финансовая политика отечественных компаний тесно связана со структурой собственности [Анкудинов и др., 2013].

\section{База данных и метод исследования}

Выборка была сформирована на основе данных по 500 крупнейшим по выручке нефинансовым открытым акционерным обществам за 2003-2011 гг. Открытые акционерные общества выбраны для анализа по причине доступности по ним информации. Анализ именно панельных данных обусловлен как самим направлением исследования решений менеджмента в сфере дивидендной политики во временном разрезе (в период кризиса), так и в целях расширения выборки и учета ненаблюдаемой разнородности (unobserved heterogeneity). Включенные в выборку компании в соответствии с Общероссийским классификатором видов экономической деятельности ОКВЭД представляют шесть секторов экономики: добыча полезных ископаемых, обрабатывающие производства, строительство, электроэнергетика, торговля и услуги, транспорт и связь.

Источником используемых в настоящем исследовании данных выступила «Система профессионального анализа рынков и компаний СПАРК» ${ }^{3}$. Анализ основывался на годовых данных, и поскольку количество наблюдений для каждой компании может быть различно, панельные данные являются несбалансированными. Однако отметим, что оценки состоятельны, если характер отсутствующих данных случаен, то есть вероятность отсутствия не зависит от величины переменной, данные по которой отсутствуют.

Описательная статистика используемых в моделировании переменных для всего периода представлена в таблице 1. Выборка представляет как компании, выплачивающие дивиденды, так и компании с нулевым дивидендным выходом. Исключение последних из выборки может привести к проблеме «смещения отбора», т.е. характеристики анализируемой выборки не будут соответствовать генеральной совокупности (см. подробнее [Deshmukh, 2003]).

Таблица 1

Описательная статистика, 2003-2011 гг.

\begin{tabular}{|c|c|c|c|c|}
\hline Переменная & Описание & Mean & $\begin{array}{l}\text { Std. } \\
\text { Dev. }\end{array}$ & $\mathrm{N}$ \\
\hline Div/Earn & Доля годовой чистой прибыли, направленная на дивиденды & 0,085 & 0,175 & 2830 \\
\hline Gov & $\begin{array}{c}\text { Дамми-переменная, }=1 \text { если акционером является правительство; }=0 \text { в } \\
\text { ином случае; }\end{array}$ & 0,256 & 0,437 & 4500 \\
\hline Publ & Статус публичной компании $(1=$ да; 0 = нет) & 0,250 & 0,432 & 4365 \\
\hline FrInv & Наличие иностранного акционера (1 = да; 0 = нет) & 0,212 & 0,409 & 4500 \\
\hline ROE & $\begin{array}{c}\text { Отношение чистой прибыли к величине собственного капитала } \\
\text { компании }\end{array}$ & 0,187 & 0,233 & 3880 \\
\hline Debt & $\begin{array}{c}\text { Доля долгового финансирования в структуре капитала (в бухгалтерской } \\
\text { оценке) }\end{array}$ & 0,509 & 0,234 & 3400 \\
\hline $\mathrm{NcAG}$ & Прирост стоимости внеоборотных активов за год & 0,228 & 0,314 & 3466 \\
\hline LnSales & Натуральный логарифм выручки компании & 23,074 & 1,633 & 4037 \\
\hline \multicolumn{5}{|c|}{ Дамми-переменные сектора экономики (по ОКВЭД) } \\
\hline ExtrInd & Добыча полезных ископаемых & 0,134 & & \\
\hline PrcInd & Обрабатывающие производства & 0,348 & & \\
\hline Cnstr & Строительство & 0,062 & & \\
\hline
\end{tabular}

\footnotetext{
${ }^{3}$ Система основывается на данных, раскрываемых компаниями, данных федеральных ведомств (Росстат, ФНС), данных СМИ (подробнее см. www.spark-interfax.ru).
} 


\begin{tabular}{|c|c|c|c|c|}
\hline EnrgInd & Электроэнергетика & 0,198 & & \\
\hline TrdSrv & Торговля и услуги & 0,176 & & \\
\hline TrnspTlcm & Транспорт и связь & 0,082 & & \\
\hline
\end{tabular}

Так, в среднем доля прибыли, направляемая на дивиденды анализируемых российских компаний, составляла $8,5 \%$ и характеризовалась высоким разбросом (о чем можно судить по высокому значению коэффициента вариации, то есть отношения стандартного отклонения к среднему значению). Однако, если опустить фирмы, которые не выплачивают дивиденды, средняя величина дивидендного выхода составит 25\%. Рисунок 1 демонстрирует среднюю величину распределяемой на дивиденды прибыли по всей выборке и по подвыборке компаний-плательщиков дивидендов; четко идентифицируется снижение дивидендов выплат в кризисные годы.

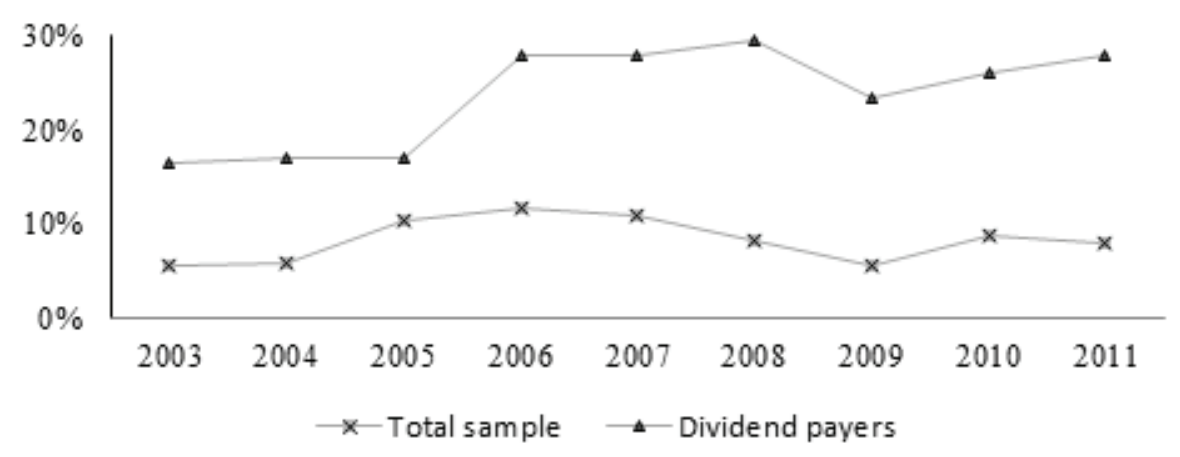

Рисунок 1. Средняя величина коэффищиента дивидендных выплат

В структуре собственности около четверти компаний государство представлено в качестве собственника. Соответствующая дамми-переменная была сформирована на основе Общероссийского классификатора форм собственности ОКФС. Также всего лишь около четверти компаний являются публичными, что не позволяет включить в анализ стоимостные (рыночные) показатели без резкого сокращения выборки. Что касается других переменных, то рентабельность собственного капитала в среднем составила 19\%, доля заемных средств - около 51\%; переменные достаточно волатильны.

Для демонстрации динамики дивидендных выплат в кризисные годы введены дамми-переменные времени (2003-2011); предположения вполне тривиальны: в условиях кризиса компании из-за запретительно высокой стоимости внешнего финансирования снижают дивиденды [Bliss et al., 2014]. Также для учета отраслевых эффектов введены дамми-переменные секторов экономики (об отраслевой структуре компаний, включенных в выборку, можно судить по средним значениям дамми-переменных сектора экономики).

Сформировавшиеся к настоящему времени подходы к распределению прибыли российских компаний таковы, что многие из них не выплачивают дивиденды вовсе. Так, из 2830 наблюдений относительно долей распределенной на дивиденды прибыли 1873 наблюдения (т.е. около 66\%) представляют нулевые значения. То есть характер распределения зависимой переменной таков, что значительная часть наблюдений сгруппирована в «нижнем хвосте». Подходящей техникой анализа цензурированных выборок выступает Тобит-моделирование. Взаимодействие между дамми-переменными лет (d2008-d2011), выпадающих на период финансово-экономического кризиса, и дамми-переменными присутствия государства в качестве собственника, публичного статуса и наличия крупного иностранного акционера введены, для тестирования выдвинутой гипотезы с целью высветить отличие практик в отношении дивидендных выплат в зависимости от характеристик структуры собственности в условия финансового кризиса. Схожий подход на основе анализа взаимодействия дамми-переменных государственной собственности и кризисного периода был использован в работе М. Корнетта и др., однако исследователи изучали не дивидендную политику, а разницу в финансовой эффективности государственных и частных банков в Юго-Восточной Азии в условиях финансового кризиса 1997 г. [Cornett et al., 2010]. На основе данных фондового рынка мы можем 
идентифицировать «начало» финансового кризиса в России, которое пришлось на второе полугодие 2008 г. Так, исторический максимум индекса РТС был установлен в мае 2008 г. (около 2500 пунктов), однако с конца лета началось резкое падение индекса, и уже в конце октября того же года индекс РТС составлял около 550 пунктов.

Оценки коэффициентов Тобит-моделей были получены методом максимального правдоподобия. С формулами расчета коэффициентов $\beta$ Тобит-модели можно ознакомиться в [StataCorp, 2009]. Все расчеты, управление данными и графический анализ были произведены с помощью программного пакета STATA 12.0.

\section{Анализ результатов}

\section{Результаты одномерного анализа}

В таблице 2 приведен тест на разницу в величине дивидендных выплат компаний в зависимости от характеристик структур собственности. Для всего периода разница средних и медианных значений для частных компаний и государственных компаний, публичных и непубличных, с представительством иностранных акционеров и без их представительства в структуре собственности положительна и статистически значима. В целом полученные результаты представляют косвенные доказательства в пользу выдвинутой гипотезы, однако финансовые характеристики компании существенно зависят от ее структуры собственности, что делает необходимым проведение дальнейшего анализа с учетом возможной эндогенности параметров структуры собственности.

На рисунке 2 представлены гистограммы распределения коэффициента дивидендных выплат компаний различных форм собственности. По оси X приведен коэффициент дивидендных выплат, по оси Y - частота исхода. Однако, в отличие от формального одномерного анализа (таблица 2), анализируется только подвыборка компаний-плательщиков дивидендов. Графический анализ нам позволяет заключить, что частные компании (по сравнению с государственными) не только более вероятно платят хоть какие-либо дивиденды, но если и распределяют прибыль, то направляют на дивиденды большую ее долю. Аналогичные выводы могут быть сделаны для публичных компаний против непубличных и (в меньшей степени) для компаний с иностранными собственниками.

Таблииа 2

Характеристики структуры собственности и дивидендные выплаты

\begin{tabular}{|c|c|c|c|c|c|c|}
\hline & \multicolumn{2}{|c|}{ Частные/государственные } & \multicolumn{2}{|c|}{ Публичные/непубличные } & \multicolumn{2}{|c|}{$\begin{array}{c}\text { Иностранная /внутренняя соб- } \\
\text { ственность }\end{array}$} \\
\hline & $\begin{array}{c}\Delta \text { Средних } \\
\text { (t-stat.) }\end{array}$ & $\begin{array}{c}\Delta \text { Медиан } \\
\text { (z-stat.) }\end{array}$ & $\begin{array}{c}\Delta \text { Средних } \\
\text { (t-stat.) }\end{array}$ & $\begin{array}{c}\Delta \text { Медиан } \\
\text { (z-stat.) }\end{array}$ & $\begin{array}{c}\Delta \text { Средних } \\
\text { (t-stat.) }\end{array}$ & $\begin{array}{c}\Delta \text { Медиан } \\
\text { (z-stat.) }\end{array}$ \\
\hline Div/Earn & $\begin{array}{c}0,042 \\
(6,10)^{* * *}\end{array}$ & - & $\begin{array}{c}0,104 \\
(14,98)^{* * *}\end{array}$ & $\begin{array}{c}0,027 \\
(15,37)^{* * *}\end{array}$ & $\begin{array}{c}0,049 \\
(6,10)^{* * *}\end{array}$ & - \\
\hline $\mathrm{NcAG}$ & $\begin{array}{r}-0,001 \\
(0,12)\end{array}$ & $\begin{array}{l}-0,003 \\
(0,50)\end{array}$ & $\begin{array}{c}0,021 \\
(1,66)^{*}\end{array}$ & $\begin{array}{l}0,006 \\
(1,36)\end{array}$ & $\begin{array}{r}-0,014 \\
(1,06)\end{array}$ & $\begin{array}{l}-0,015 \\
(0,53)\end{array}$ \\
\hline ROE & $\begin{array}{c}0,057 \\
(6,65)^{* * *}\end{array}$ & $\begin{array}{c}0,068 \\
(7,44)^{* * *}\end{array}$ & $\begin{array}{c}-0,037 \\
(4,26)^{* * *}\end{array}$ & $\begin{array}{c}-0,065 \\
(5,39) * * *\end{array}$ & $\begin{array}{c}0,018 \\
(2,07)^{* *}\end{array}$ & $\begin{array}{c}0,019 \\
(2,04)^{* *}\end{array}$ \\
\hline Debt & $\begin{array}{l}-0,005 \\
(0,51)\end{array}$ & $\begin{array}{r}-0,017 \\
(0,59)\end{array}$ & $\begin{array}{c}-0,037 \\
(4,05)^{* * *}\end{array}$ & $\begin{array}{c}-0,079 \\
(4,02)^{* * *}\end{array}$ & $\begin{array}{c}0,022 \\
(2,30)^{* *}\end{array}$ & $\begin{array}{c}0,030 \\
(2,27)^{* *}\end{array}$ \\
\hline LnSales & $\begin{array}{l}-0,099 \\
(1,67)^{*}\end{array}$ & $\begin{array}{c}-0,090 \\
(2,14)^{* *}\end{array}$ & $\begin{array}{c}1,018 \\
(17,65)^{* * *}\end{array}$ & $\begin{array}{c}0,809 \\
(18,69)^{* * *}\end{array}$ & $\begin{array}{c}0,255 \\
(4,08)^{* * *}\end{array}$ & $\begin{array}{c}0,030 \\
(5,62)^{* * *}\end{array}$ \\
\hline
\end{tabular}

Примечание. Определение и порядок расчета переменных приведены в таблице 1. Сравниваются средние и медианные значения переменных для частных компаний и государственных компаний, публичных и непубличных, с представительством иностранных акционеров и без их представительства в структуре собственности; тестирование статистической значимости различий в средних значениях проводилось с помоицью t-теста, различий в медианных значениях - непараметрического Mann-Whitnеy z-теста. Tест медианньх значений не приводится, если медианное значение по всей выборке равно 0; однако если анализировать только даннье 
по плательщикам дивидендов, то разница медиан дивидендного выхода частных/государственных компаний составит 0,071 ( $\left.z=5,10^{* * *}\right)$, для иностранной/национальной собственности - составит 0,128 ( $\left.z=4,63 * * *\right)$.

***-уровень значимости 1\%, **-уровень значимости 5\%, *-уровень значимости 10\%.

Мы разбили выборку на два периода - 2003-2007 гг. и 2008-2011 гг. и проанализировали, как отличались средние и медианные значения по исследуемым переменным для плательщиков и неплательщиков дивидендов (таблица 3). Сравнение также поддерживает нашу гипотезу о зависимости дивидендной политики и характеристик структуры собственности. В то же время следует отметить, что в предкризисный период (Panel A) государственные и частные компании характеризовались примерно одной вероятностью выплаты дивидендов, однако в посткризисный период частные компании выплачивали хотя бы какие-либо дивиденды значительно чаще. Компании - плательщики дивидендов в среднем более прибыльны, крупнее и менее левереджированы (разницы средних и медиан значимы на 1\%-ном уровне). В то же время в докризинсый период наиболее активно инвестирующие компании также более вероятно платили какие-либо дивиденды (хотя оценки в целом ненадежны, однако в посткризисный период подобная ситуация уже не наблюдалась.
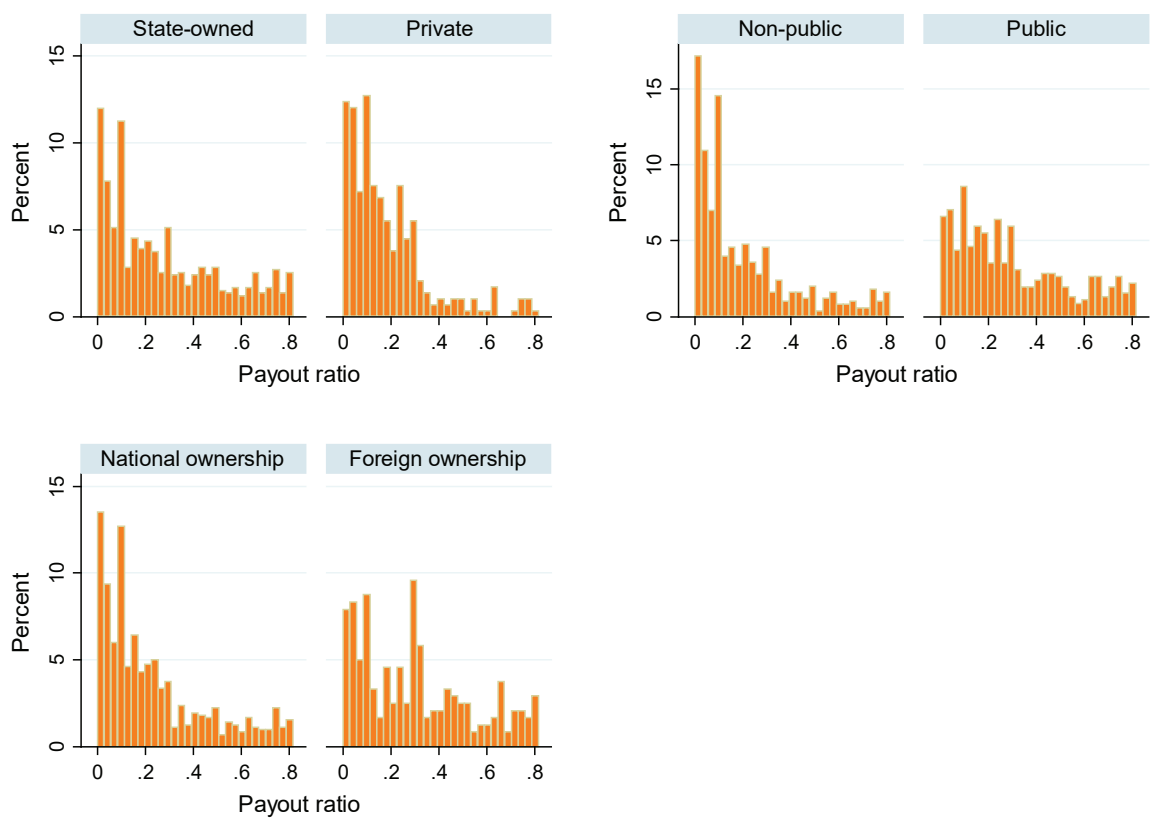

Рисунок 2. Гистограммы распределения коэффициента дивидендных выплат компаний различных форм собственности

Таблица 3

Тест значимых различий плательщиков и неплательщиков дивидендов

\begin{tabular}{|c|c|c|c|c|c|c|}
\hline & $\begin{array}{l}\text { Mean, } \\
\text { dividend } \\
\text { payers }\end{array}$ & $\begin{array}{l}\text { Mean, non- } \\
\text { dividend } \\
\text { payers }\end{array}$ & $\begin{array}{c}\text { P-value for } \\
\text { t-test }\end{array}$ & $\begin{array}{l}\text { Median, } \\
\text { dividend } \\
\text { payers }\end{array}$ & $\begin{array}{l}\text { Median, non- } \\
\text { dividend } \\
\text { payers }\end{array}$ & $\begin{array}{c}\text { P-value } \\
\text { for Mann- } \\
\text { Whitney test }\end{array}$ \\
\hline \multicolumn{7}{|c|}{$\begin{array}{c}\text { Panel A: (2003-2007) } \\
\quad N=597 \text { vs. } 969\end{array}$} \\
\hline Gov & 0,321 & 0,320 & 0,978 & 0,000 & 0,000 & - \\
\hline Publ & 0,484 & 0,156 & 0,000 & 0,000 & 0,000 & - \\
\hline FrInv & 0,244 & 0,181 & 0,002 & 0,002 & 0,002 & - \\
\hline ROE & 0,224 & 0,181 & 0,000 & 0,182 & 0,148 & 0,000 \\
\hline Debt & 0,466 & 0,529 & 0,000 & 0,441 & 0,541 & 0,000 \\
\hline $\mathrm{NcAG}$ & 0,290 & 0,238 & 0,006 & 0,166 & 0,127 & 0,000 \\
\hline LnSales & 23,380 & 22,320 & 0,000 & 23,193 & 22,521 & 0,000 \\
\hline \multicolumn{7}{|c|}{$\begin{array}{c}\text { Panel B: }(2008-2011) \\
\quad N=537 \text { vs. } 969\end{array}$} \\
\hline Gov & 0,275 & 0,379 & 0,000 & 0,000 & 0,000 & - \\
\hline
\end{tabular}




\begin{tabular}{|c|c|c|c|c|c|c|c|}
\hline Publ & 0,461 & 0,286 & 0,000 & & 0,000 & 0,000 & - \\
\hline FrInv & 0,261 & 0,196 & 0,010 & & 0,002 & 0,002 & - \\
\hline ROE & 0,219 & 0,102 & 0,000 & & 0,170 & 0,069 & 0,000 \\
\hline Debt & 0,494 & 0,517 & 0,133 & & 0,501 & 0,530 & 0,141 \\
\hline NcAG & 0,193 & 0,201 & 0,640 & & 0,129 & 0,113 & 0,320 \\
\hline LnSales & 24,230 & 23,440 & 0,000 & & 23,970 & 23,400 & 0,000 \\
\hline
\end{tabular}

Примечание: представлены тесты сравнения средних значений (t-mест; H0: D теапs = 0) и медиан (Мапп-

Whitney test; H0: D medians =0) по анализируемым переменным для плательщиков и неплательщиков дивидендов. Определение и порядок расчета переменных приведены в таблище 1.

Продолжением подобного анализа выступило сравнение величины дивидендных выплат компаний в зависимости от их финансовых характеристик (уровень доходности, финансовый леверидж, инвестиционная активность). Рисунок 3 иллюстрирует подобную зависимость для компаний-плательщиков дивидендов в пред- и послекризисный периоды; по оси Ү приводится значение коэффициента дивидендных выплат; величина круга отражает размер компании (размер определяется на основе логарифмированного объема продаж компании). Данные показывают, что позитивная зависимость прибыльности и доли прибыли, распределяемой на дивиденды, усиливается в посткризисный период. В то же время имеются некоторые свидетельства отрицательной зависимости финансового левериджа и дивидендных выплат, которая становится менее выраженной в посткризисный период. Но следует учитывать, что аналитические возможности линейных парных регрессий весьма ограничены.
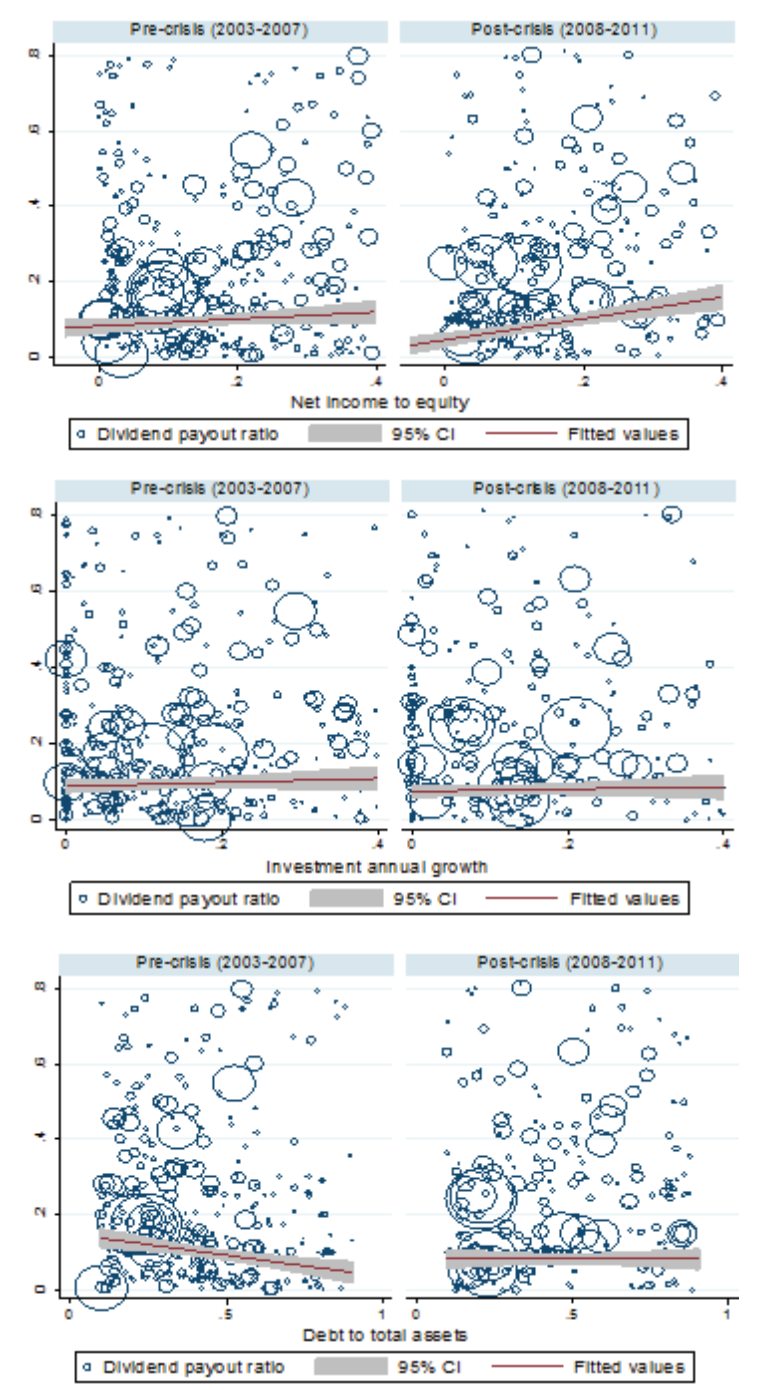

Рисунок 3. Зависимость величины дивидендных выплат и финансовых характеристик российских компаний

\section{Результаты многовариантного анализа}

В таблице 4 представлены результаты оценок Тобит-регрессий со случайными эффектами дивидендных выплат российских компаний. Значение статистики Вальда позволяет откло- 
нить нулевую гипотезу о совместной незначимости факторов моделей 1-5 с высоким уровнем надежности: величины p-value $<0,000$. Величина коэффициента Rho, отражающая долю объясненной дисперсии панельным компонентом (равен приблизительно 0,6 для всех моделей), показывает более высокую статистическую мощность Тобит-моделей со случайными эффектами по сравнению со сквозными моделями. Формальный LR-тест позволяет отвергнуть нулевую гипотезу о незначимости панельного компонента (о равенстве Rho нулю) на 1\%-ном уровне значимости для всех моделей. Это может свидетельствовать о значительном влиянии ненаблюдаемых индивидуальных эффектов российских компаний на решения в отношении распределения прибыли, например таких, как предпочтения мажоритарных акционеров, контроль со стороны менеджмента и др.

Прежде всего на основе полученных оценок мы можем заключить, что разницу дивидендных выплат госкомпаний и частных компаний составляют именно выплаты а кризисный период; так, коэффициенты при дамми-переменной государственной собственности отрицательны и значимы в тех моделях, где не были представлены взаимодействия дамми-переменных госсобственности и кризисных лет (колонки 2 и 5). Госкомпании платили меньше дивидендов именно в кризисный период, что предоставляет некоторые свидетельства в пользу выдвинутой гипотезы. Полученные по панельным данным результаты также согласуются с обсуждаемыми выше оценками в рамках одномерного анализа. Полученные результаты могут быть объяснены теорией А. Шлейфера и Р. Вишны, согласно которой действия бюрократов-управленцев могут быть в первую очередь движимы политическими интересами, а не экономическими соображениями максимизации акционерной доходности [Shleifer and Vishny, 1997]. Так, интерпретируя полученные оценки формально, отметим, что компании с государственным участием в период финансового кризиса действительно выплачивали существенно меньшие дивиденды по сравнению с частными компаниями. При прочих равных сам факт присутствия в качестве акционера государства, согласно Тобит-оценкам модели 5 , ассоциировался с меньшей на 14\% долей распределенной на дивиденды прибыли в 2008 г. (р < 0,05), на 7\% - в 2009 г., на $9 \%$ - в 2010 г. ( $<0.10)$, на 12\% - в 2011 г. (р < 0.05), что, принимая во внимание практику дивидендных выплат российских компаний, представляется весьма значительной величиной. Дополнительно отметим, что, несмотря на наличие распоряжений правительства об обязательном для госкомпаний минимуме распределяемой на дивиденды прибыли, эти документы фактически носят лишь рекомендательный характер, и, по всей видимости, финансовый кризис выступил достаточным основанием для их приостановления.

Тобит-оценки детерминант дивидендных выплат

\begin{tabular}{|c|c|c|c|c|c|}
\hline & \multicolumn{5}{|c|}{ Коэффициент дивидендных выплат } \\
\hline & $(1)$ & $(2)$ & $(3)$ & $(4)$ & $(5)$ \\
\hline Gov & $-0,071$ & $-0,019$ & $-0,073$ & $-0,070$ & $-0,013$ \\
\hline & $(1,73)^{*}$ & $(0,43)$ & $(1,81)^{*}$ & $(1,72)^{*}$ & $(0,30)$ \\
\hline FrInv & 0,029 & 0,026 & 0,027 & 0,043 & 0,026 \\
\hline & $(0,66)$ & $(0,60)$ & $(0,64)$ & $(0,93)$ & $(0,56)$ \\
\hline Publ & 0,211 & 0,205 & 0,284 & 0,211 & 0,202 \\
\hline & $(4,62)^{* * *}$ & $(4,52)^{* * *}$ & $(6,01)^{* * *}$ & $(4,62)^{* * *}$ & $(6,68)^{* * *}$ \\
\hline ROE & 0,195 & 0,195 & 0,193 & 0,197 & 0,185 \\
\hline & $(3,75)^{* * *}$ & $(3,77)^{* * *}$ & $(3,77)^{* * *}$ & $(3,79)^{* * *}$ & $(3,64)^{* * *}$ \\
\hline Debt & $-0,166$ & $-0,162$ & $-0,154$ & $-0,164$ & $-0,134$ \\
\hline & $(2,98)^{* * *}$ & $(2,92)^{* * *}$ & $(2,80)^{* * *}$ & $(2,95)^{* * *}$ & $(2,44)^{* *}$ \\
\hline NcAG & $-0,009$ & $-0,004$ & $-0,027$ & $-0,009$ & $-0,019$ \\
\hline & $(0,36)$ & $(0,14)$ & $(1,03)$ & $(0,35)$ & $(0,73)$ \\
\hline LnSales & 0,068 & 0,071 & 0,066 & 0,068 & 0,066 \\
\hline & $(5,08)^{* * *}$ & $(5,34)^{* * *}$ & $(5,03)^{* * *}$ & $(5,11)^{* * *}$ & $(5,53)^{* * *}$ \\
\hline Gov*d2008 & & $-0,149$ & & & $-0,136$ \\
\hline
\end{tabular}




\begin{tabular}{|c|c|c|c|c|c|}
\hline & & $(2,75)^{* * *}$ & & & $(2,55)^{* *}$ \\
\hline \multirow[t]{2}{*}{ Gov*d2009 } & & $-0,085$ & & & $-0,066$ \\
\hline & & $(1,47)$ & & & $(1,15)$ \\
\hline \multirow[t]{2}{*}{ Gov*d2010 } & & $-0,117$ & & & $-0,088$ \\
\hline & & $(2,21)^{* *}$ & & & $(1,77)^{*}$ \\
\hline \multirow[t]{2}{*}{ Gov*d2011 } & & $-0,137$ & & & $-0,123$ \\
\hline & & $(2,20)^{* *}$ & & & $(2,19)^{* *}$ \\
\hline \multirow[t]{2}{*}{ Publ*d2008 } & & & $-0,189$ & & $-0,173$ \\
\hline & & & $(3,99)^{* * *}$ & & $(3,65)^{* * *}$ \\
\hline \multirow[t]{2}{*}{ Publ*d2009 } & & & $-0,187$ & & $-0,177$ \\
\hline & & & $(3,57)^{* * *}$ & & $(3,38)^{* * *}$ \\
\hline \multirow[t]{2}{*}{ Publ*d2010 } & & & $-0,141$ & & $-0,099$ \\
\hline & & & $(2,92)^{* * *}$ & & $(2,18)^{* *}$ \\
\hline \multirow[t]{2}{*}{ Publ*d2011 } & & & $-0,153$ & & $-0,178$ \\
\hline & & & $(2,51)^{* *}$ & & $(3,41)^{* * *}$ \\
\hline \multirow[t]{2}{*}{ FrInv*d2008 } & & & & $-0,062$ & $-0,043$ \\
\hline & & & & $(1,14)$ & $(0,81)$ \\
\hline \multirow[t]{2}{*}{ FrInv *d2009 } & & & & $-0,026$ & 0,003 \\
\hline & & & & $(0,41)$ & $(0,04)$ \\
\hline \multirow[t]{2}{*}{ FrInv $* \mathrm{~d} 2010$} & & & & $-0,059$ & $-0,030$ \\
\hline & & & & $(1,00)$ & $(0,51)$ \\
\hline \multirow[t]{2}{*}{ FrInv $*$ d2011 } & & & & 0,046 & 0,049 \\
\hline & & & & $(0,67)$ & $(0,75)$ \\
\hline Time dummies & Yes & Yes & Yes & Yes & Yes \\
\hline Industry dummies & Yes & Yes & Yes & Yes & Yes \\
\hline $\mathrm{N}$ & 2030 & 2030 & 2030 & 2030 & 2030 \\
\hline Wald $\chi^{2}$ & 160,57 & 178,96 & 197,03 & 170,23 & 209,07 \\
\hline
\end{tabular}

Примечание. В таблице представлены оченки коэффициентов Тобит-регрессий со случайньми эффектами дивидендного выхода отечественных компаний. В модели включены взаимодействия дамми-переменных характеристик структуры собственности и дамми-переменные кризисных лет. Определения переменных представлены в таблице 1, в скобках приведены значения t-статистик.

Полученные оценки также демонстрируют сильный позитивный эффект влияния статуса публичности на дивидендные выплаты российских компаний (коэффициенты значимы во всех моделях на 1\%-ном уровне). Так, при прочих равных условиях доля прибыли, распределяемая на дивиденды, приблизительно выше на $20 \%$ и p $<0,01$. Влияние достаточно мощное, учитывая скупость российских компаний в плане выплаты дивидендов в целом. В то же время коэффициенты перед взаимодействиями дамми-переменных статуса публичности и кризисных лет также статистически значимы и имеют отрицательный знак. Последнее может свидетельствовать о том, что практика выплаты щедрых дивидендов публичными компаниями, характерная для них в финансово благополучные годы, резко сменяется на более скупую дивидендную политику в условиях финансовых ограничений кризисных лет. Иными словами, разница в величине выплаченных дивидендов публичных и непубличных компаний в условиях финансового кризиса снижается; немалую роль в этом играет то, что некоторые даже публичные компании прекращают выплачивать какие-либо дивиденды вовсе, о чем можно судить по меньшей разнице средних значений переменной Publ для плательщиков и неплательщиков дивидендов в посткризисный период в таблице 3. Полученные результаты в целом соответствуют выводам предыдущих работ, которые показывают, что практики корпоративного управления и уровень защиты миноритарных инвесторов как на уровне стран, так и на уровне компаний (которые более вероятно будут более строгими для публичных компаний, хотя бы в силу требований регуляторов) позитивно ассоциируются с величиной выплачиваемых дивидендов [La Porta et al., 2000]. Похожие свидетельства имеются и по развивающимся рынкам; в частности, Дж. Савицки показывает, что зависимость между корпоративным управлением и дивидендными выплатами в странах Юго-Восточной Азии в период кризиса 1997 г. становится весьма отчетливой [Sawicki, 2009]. 
Однако мы не находим статистически значимой зависимости дивидендных выплат и наличия в структуре собственности иностранного акционера. Коэффициенты как перед соответствующими дамми-переменными, так и взаимодействиями дамми-переменных незначимы. Впрочем, следует отдельно отметить ограничение подобного анализа. Используемые нами данные не позволяют достоверно определить, действительно ли компания принадлежит нерезидентам, или же собственники на самом деле резиденты, использующие офшорные схемы (весьма распространенная практика в России).

Кратко остановимся также на влиянии на дивидендные выплаты российских компаний прочих факторов, направление воздействия которых в целом согласуется с полученными в рамках одномерного анализа результатами. Так, прибыльность компаний оказывает мощное положительное воздействие на величину выплачиваемых дивидендов. Отметим, что прибыльность компании в условиях слабоэффективного рынка капитала в силу расширенной информационной асимметрии еще более акцентирует менеджмент на внутренних источниках финансирования [Лебедев, 2015]. Кроме того, чтобы распределить прибыль, ее надо сначала заработать. Также позитивное статистически значимое во все периоды позитивное влияние на дивидендные выплаты оказывает размер компании. Полученные оценки соответствуют предыдущим исследованиям [Fama and French, 2001; Ferris, 2006], которые демонстрируют, что вероятность выплаты дивидендов положительно ассоциируется с размером и прибыльностью. Уровень финансового левериджа негативно связан с величиной выплачиваемых дивидендов, коэффициенты же перед переменной инвестиционной активности статистически менее надежны.

\section{Надежность полученных результатов}

Говоря о надежности полученных результатов, отметим результаты ряда диагностических тестов. Были рассчитаны VIF-факторы (Variance Inflation Factor, VIF) для тестирования гипотезы о наличии мультиколлинеарности. Значение VIF-факторов для независимых переменных позволяет отклонить гипотезу о мультиколлинеарности для всех моделей.

Результаты теста Бройша-Пагана на гетероскедастичность подтверждают наличие гетероскедастичности во всех моделях. Для проверки результатов Тобит-моделей была использована так называемая «двухчастная модель». Двухчастная модель предполагает «разбиение» Тобитмодели на две части; как бы оцениваются два независимых решения: первое - платить ли дивиденды, и второе - какую величину дивидендов выплатить. Первая часть модели оценивается через логит-модель, вторая - через линейные регрессии. Для устранения же проблемы гетероскедастичности в регрессиях использовались значения двустороннего $t$-теста для $\beta$ коэффициентов на основе робастных стандартных ошибок (Huber/White/sandwich estimator). Также, чтобы ослабить возможную проблему эндогенности, мы анализируем модели с фиксированными эффектами. Мы получили результаты, соответствующие обсуждаемым выше (результаты представлены в таблице 5). Коэффициенты перед взаимодействием дамми-переменных госсобственности и кризисных лет демонстрируют, что госкомпании существенно сократили дивидендные выплаты в условиях кризиса. Публичные компании также переключились на более «прижимистую» дивидендную политику. Однако сами дамми-переменные характеристик структуры собственности не могут быть протестированы в моделях с фиксированными эффектами ввиду практической неизменяемости данных переменных во временном измерении. Прибыльность компании и ее размер положительно, а уровень финансового левериджа отрицательно, как и ранее, ассоциируются с дивидендными выплатами; однако статистическая надежность оценок несколько снизилась, что может свидетельствовать об их коррелированности с ненаблюдаемыми индивидуальными эффектами.

Следует также отметить ряд ограничений проведенного анализа. Во-первых, дивидендные выплаты могут производиться не только денежными средствами, но и через выкуп собственных акций (однако подобная практика не сильно распространена в России). Во-вторых, в соответствии со стандартами бухгалтерской отчетности величина прибыли может варьироваться в зависимости от учетных процедур и сделанных допущений. В-третьих, авторы отдают 
себе отчет в том, что регрессии показывают лишь корреляции, а не каузальность исследуемых зависимостей.

Таблица 5

Регрессии с фиксированными эффектами в рамках «двухчастной» модели

\begin{tabular}{|c|c|c|}
\hline & \multicolumn{2}{|c|}{ Div/Earn } \\
\hline & Logit FE & GLS FE \\
\hline \multirow[t]{2}{*}{ ROE } & 3,063 & $-0,007$ \\
\hline & $(5,30)^{* * *}$ & $(0,27)$ \\
\hline \multirow[t]{2}{*}{ Debt } & $-3,100$ & $-0,059$ \\
\hline & $(4,10)^{* * * *}$ & $(1,96)^{*}$ \\
\hline \multirow[t]{2}{*}{ Ncag } & 0,469 & $-0,012$ \\
\hline & $(2,01)^{* *}$ & $(0,96)$ \\
\hline \multirow[t]{2}{*}{ LnSales } & 0,356 & 0,012 \\
\hline & $(1,74)^{*}$ & $(2,26)^{* *}$ \\
\hline \multirow[t]{2}{*}{ Gov*d2008 } & $-2,300$ & $-0,046$ \\
\hline & $(3,52)^{* * *}$ & $(2,13)^{* *}$ \\
\hline \multirow[t]{2}{*}{ Gov*d2009 } & $-1,022$ & $-0,017$ \\
\hline & $(1,59)$ & $(0,84)$ \\
\hline \multirow{2}{*}{ Gov*d2010 } & $-1,308$ & $-0,038$ \\
\hline & $(2,11)^{* *}$ & $(1,68)^{*}$ \\
\hline \multirow[t]{2}{*}{ Gov*d2011 } & $-1,262$ & $-0,048$ \\
\hline & $(1,81)^{*}$ & $(1,82)^{*}$ \\
\hline \multirow[t]{2}{*}{ Publ*d2008 } & $-1,937$ & $-0,089$ \\
\hline & $(3,67)^{* * *}$ & $(2,92) * * *$ \\
\hline \multirow[t]{2}{*}{ Publ*d2009 } & $-1,018$ & $-0,092$ \\
\hline & $(1,82)^{*}$ & $(3,82) * * *$ \\
\hline \multirow[t]{2}{*}{ Publ*d2010 } & $-0,579$ & $-0,072$ \\
\hline & $(1,08)$ & $(2,51)^{* *}$ \\
\hline \multirow[t]{2}{*}{ Publ*d2011 } & $-0,073$ & $-0,118$ \\
\hline & $(0,11)$ & $(3,78)^{* * *}$ \\
\hline \multirow[t]{2}{*}{ FrInv*d2008 } & $-0,433$ & $-0,003$ \\
\hline & $(0,75)$ & $(0,11)$ \\
\hline \multirow[t]{2}{*}{ FrInv *d2009 } & 0,225 & 0,009 \\
\hline & $(0,35)$ & $(0,31)$ \\
\hline \multirow[t]{2}{*}{ FrInv *d2010 } & $-0,322$ & $-0,012$ \\
\hline & $(0,48)$ & $(0,38)$ \\
\hline \multirow[t]{2}{*}{ FrInv *d2011 } & 0,934 & 0,028 \\
\hline & $(1,09)$ & $(0,77)$ \\
\hline Time dummies & Yes & Yes \\
\hline Industry dummies & No & No \\
\hline $\mathrm{N}$ & 917 & 2030 \\
\hline $\mathrm{LR} \chi^{2} / \mathrm{F}$ & 172,52 & 4,08 \\
\hline
\end{tabular}

Примечание: В таблице представлены оценки Логит- и GLS (обобщенный MHК) регрессий с фиксированными эффектами детерминант дивидендных выплат. В модели включены взаимодействия дамми-переменных характеристик структуры собственности и дамми-переменные кризисных лет. Определения переменных представлены в таблице 1, в скобках приведены робастные значения t-статистики.

\section{Заключение}

Полученные в рамках эмпирического анализа дивидендных выплат крупнейших отечественных нефинансовых компаний результаты позволяют сделать ряд выводов, которые могут внести вклад в формирование методологических основ повышения эффективности финансовой политики российских компаний. Результаты эмпирического анализа позволяют сформулиро- 
вать рекомендации по некоторым экономическим проблемам, находящимся в центре общественного внимания, в частности относительно приватизационных процессов.

Сформировавшиеся к настоящему времени подходы к распределению прибыли российских компаний таковы, что многие из них не выплачивают дивиденды вовсе. Так, из 2830 наблюдений относительно долей распределенной на дивиденды прибыли 1873 наблюдения (т.е. около 66\%) представляют нулевые значения. В среднем доля прибыли, направляемая на дивиденды, составляла 8,5\% и характеризовалась высоким разбросом в пространственном и временном измерении (четко идентифицируется снижение дивидендов выплат в кризисные годы). Однако, если опустить компании, которые не выплачивают дивиденды, средняя величина дивидендного выхода составит 25\%. Сравнение подобной статистики с данными предыдущих эмпирических работ позволяет заключить, что дивидендные выплаты российских компаний ниже дивидендного выхода компаний как с развитых, так и с многих развивающихся рынков.

Характеристики структуры собственности оказывают значительное влияние на проводимую компаниями дивидендную политику. Для всего периода (2003-2011 гг.) разница средних и медианных значений для частных компаний и государственных компаний, публичных и непубличных, с представительством иностранных акционеров и без их представительства в структуре собственности положительна и статистически значима. Полученные оценки также показывают, что частные компании (по сравнению с государственными) не только более вероятно платят хоть какие-либо дивиденды, но если и распределяют прибыль, то направляют на дивиденды большую ее долю. Аналогичные выводы могут быть сделаны для публичных компаний и (в значительно меньшей степени) для компаний с иностранными собственниками. Компании-плательщики дивидендов в среднем более прибыльны, крупнее и менее левереджированы.

В то же время следует отметить, что в предкризисный период государственные и частные компании характеризовались примерно равной величиной дивидендного выхода, однако в посткризисный период частные компании распределяли на дивиденды большую часть прибыли. Практика выплаты щедрых дивидендов, характерная для публичных компаний в финансово благополучные годы, резко сменяется на более скупую дивидендную политику в условиях финансовых ограничений кризисных лет. Иными словами, разница в величине выплаченных дивидендов публичных и непубличных компаний в условиях финансового кризиса снижается; немалую роль в этом играет то, что некоторые даже публичные компании прекращают выплачивать какие-либо дивиденды вовсе.

Полученные оценки также показывают, что ненаблюдаемые индивидуальные характеристики компании выступают важными детерминантами дивидендной политики. Прибыльность, размер компании позитивно коррелированы с величиной выплачиваемых дивидендов. В то же время компании с более высокой долей долга в структуре капитала выплачивают меньшие дивиденды. Позитивная зависимость прибыльности и доли прибыли распределяемой на дивиденды усиливается в посткризисный период. Одновременно негативная зависимость финансового левериджа и дивидендных выплат становится менее выраженной в посткризисный период.

\section{Благодарности}

Авторы выражают благодарность Российскому научному фонду; исследование выполнено при поддержке гранта № 16-18-10432.

\section{Список литературы}

1. Анкудинов А.Б., Биктемирова М.Х., Лебедев О.В. Анализ факторов структуры финансирования российских нефтяных компаний // Нефтяное хозяйство. 2013. № 8. С. 66-70.

2. Анкудинов А.Б., Лебедев О.В. Детерминанты создания акционерной стоимости российскими компаниями // Корпоративные финансы. 2014. № 1(29). С. 33-49. 
3. Зальцман А.А. Особенности дивидендной политики российских компаний с кросслистингом // Финансовые исследования. 2014. № 4(45). С. 207-221.

4. Ивашковская И.В., Кукина Е.Б. Детерминанты экономической прибыли крупных российских компаний // Корпоративные финансы. 2009. № 4. С. 18-33.

5. Кери И.Т., Громова Е.И., Синельщикова Н.В. Особенности дивидендных выплат в российских компаниях // Современные тенденции в экономике и управлении: новый взгляд. 2013. № 20. С. 173-179.

6. Лебедев О.В. Формирование акционерной стоимости на несовершенном рынке капитала: дис. ... канд. эконом. наук. Казань, 2015. 191 с.

7. Пирогов Н.К., Волкова Н.Н. Дивидендная политика компаний на развивающихся рынках // Корпоративные финансы. 2009. № 4(12). С. 57-78.

8. Ружанская Л., Лукьянов С. Особенности дивидендной политики российских компаний и интересы инвесторов // Вопросы экономики. 2012. № 3. С. 132-146.

9. Теплова Т.В. Влияние дивидендных выплат на рыночную оценку российских компаний: эмпирическое исследование методом событийного анализа на российских и зарубежных торговых площадках // Аудит и финансовый анализ. 2008. № 2. С. 1-15.

10. Теплова Т.В. Реакция цен акций на объявления денежных дивидендов: сигнализирование на российском рынке до и после кризиса // Финансовый менеджмент. 2011. № 1. C. 13-25.

11. Шагалеева Г.Б. Особенности дивидендной политики компаний развивающихся рынков капитала: дис. ... канд. эконом. наук. Москва, 2011. 181 с.

12. Almeida H., Campello M. and Weisbach M.S. (2011) Corporate financial and investment policies when future financing is not frictionless. Journal of Corporate Finance, vol. 17, no. 3, pp. 675-693.

13. Bebczuk R. (2005) Corporate governance and ownership: measurement and impact on corporate performance and dividend policies in Argentina. Center for Financial Stability working paper.

14. Bliss B.A., Cheng Y. and Denis D.J. (2014) Corporate payout, cash retention, and the supply of credit: Evidence from the 2008-2009 credit crisis. Journal of Financial Economics, vol. 115, no. 3, pp. 521-540.

15. Boubakri N. and Cosset J.C. (1998) The financial and operating performance of newly privatized firms: evidence from developing countries. The Journal of Finance, vol. 53, no. 3, pp. 1081- 1110 .

16. Brav A., Graham J.R., Harvey C.R. and Michaely R. (2005) Payout policy in the 21 st century. Journal of Financial Economics, vol. 77, no. 3, pp. 483-527.

17. Cornett M.M., Guo, L., Khaksari S. and Tehranian H. (2010) The impact of state ownership on performance differences in privately-owned versus state-owned banks: an international comparison. Journal of Financial Intermediation, vol. 19, no. 1, pp. 74-94.

18. Daniel N.D., Denis D. and Naveen L. (2008) Sources of financial flexibility: Evidence from cash flow shortfalls. Working Paper, Drexel University, Purdue University and Temple University.

19. Deshmukh S. (2003) Dividend initiations and asymmetric information: a hazard model. Financial Review, vol. 38, no. 3, pp. 351-368.

20. Dittmar A., Mahrt-Smith J. and Servaes H. (2003) International corporate governance and corporate cash holdings. Journal of Financial and Quantitative Analysis, vol. 38, no. 1, pp. $111-133$.

21. D'souza J. and Megginson W.L. (1999) The financial and operating performance of privatized firms during the 1990s. The Journal of Finance, vol. 54, no. 4, pp. 1397-1438. 
22. Faccio M., Lang L.H. and Young L. (2001) Dividends and expropriation. American Economic Review, vol. 91, no. 1, pp. 54-78.

23. Fama E.F. and French K.R. (2001) Disappearing dividends: changing firm characteristics or lower propensity to pay? Journal of Financial Economics, vol. 60, no. 1, pp. 3-43.

24. Ferris S.P., Sen N. and Yui, H.P. (2006) God save the Queen and her dividends: corporate payouts in the United Kingdom. The Journal of Business, vol. 79, no. 3, pp. 1149-1173.

25. Floyd E., Li N. and Skinner D.J. (2014) Payout policy through the financial crisis: the growth of repurchases and the resilience of dividends. Chicago Booth Research Paper 12-01.

26. Khan T. (2006) Company dividends and ownership structure: evidence from UK panel data. The Economic Journal, vol. 116, no. 510, pp. 172-189.

27. Kowalewski O., Stetsyuk I. and Talavera O. (2008) Does corporate governance determine dividend payouts in Poland? Post-Communist Economies, vol. 20, no. 2, pp. 203-218.

28. La Porta R., Lopez-de-Silanes F., Shleifer A., Vishny R. 2000. Agency problems and dividend policies around the world. The Journal of Finance, vol. 55, no. 1, pp. 1-33.

29. Leary M.T. and Michaely R. (2011) Determinants of dividend smoothing: Empirical evidence. Review of Financial Studies, vol. 24, no. 10, pp. 3197-3249.

30. Mian A. and Suf A. (2010) The great recession: Lessons from microeconomic data. The American Economic Review, vol. 100, no. 2, pp. 51-56.

31. Sawicki J. (2009) Corporate governance and dividend policy in Southeast Asia pre-and postcrisis. The European Journal of Finance, vol. 15, no. 2, pp. 211 and 230.

32. Shleifer A. and Vishny R.W. (1997) A survey of corporate governance. The Journal of Finance, vol. 52, no. 2, pp. 737-783.

33. StataCorp (2009) Stata longitudinal data reference manual: release 11.0. Stata Corporation Press, College Station, Texas.

\title{
DIVIDEND PAYOUTS OF RUSSIAN COMPANIES AGAINST THE BACKDROP OF FINANCIAL CRISIS
}

Andrei B. Ankudinov, Associate professor, Department of Corporate Finance, Kazan Federal University, e-mail: ankudia@mail.ru

\author{
Oleg V. Lebedev, \\ Assistant, Department of Corporate Finance, Kazan Federal University; \\ Research fellow at Innopolis University \\ E-mail:lebolegan@yandex.ru
}

\begin{abstract}
The article presents results of empirical study of trends in dividend payments of national companies against the backdrop of crisis-period credit crunch. The analysis is based on the panel data; the sample is formed by data covering the 2003-2011 period for the largest companies representing nonfinancial sector of national economy. Research method was comprised of two stages: first the univariate analysis was performed of relationship between individual characteristics of companies and their dividend policies, then - multivariate analysis based on regression testing of panel data. The obtained estimates show that the approaches to profit distribution developed by Russian companies so far result in many companies not paying any dividends at all (66\% of observations representing dividend payouts amount to zero values). On average the payout ratio was around $8.5 \%$, reaching $25 \%$ for the subsample of companies - payers of dividends. This is lower than dividend payouts of companies representing developed as well as most of developing markets. Besides, the payout
\end{abstract}


ratios sample is characterized by significant variation of data with time as well across the sample. Decrease in dividend payments during the crisis years can be distinctly identified. In the pre-crisis years state-owned and privately-owned companies had maintained approximately the same level of dividend payout ratio while in the post-crisis period the latter distributed larger portion of corporate profits. Differences in the amounts of dividends paid by public vs. non-public companies go down in the crisis years, however the first are still characterized by much more generous dividend policy. Unobserved individual characteristics of companies appear to affect significantly profit distribution. Company profitability and size are positively while financial leverage is negatively related to the likelihood of dividend payments as well as to the actual amount of dividends paid. Positive relation between profitability and payout ratio becomes stronger in the post-crisis period, while at the same time the negative relation between financial leverage and dividend payments tend to become less pronounced.

Key words: dividends, dividend policy, Russian companies, panel data, financial crisis, state-owned companies

JEL: G35, G32

\section{References}

1. Almeida H., Campello M. and Weisbach M.S. (2011) Corporate financial and investment policies when future financing is not frictionless. Journal of Corporate Finance, vol. 17, no. 3, pp. 675-693.

2. Ankudinov A.B., Biktemirova M.H. and Lebedev O.V. (2013) Analiz faktorov struktury finansirovanija rossijskih neftjanyh kompanij [Financial structure determinants analysis of Russian oil companies]. Neftyanoe khozyaistvo - Oil Industry, no. 8, pp. 66-70.

3. Ankudinov A.B. and Lebedev O.V. (2014) Determinanty sozdanija akcionernoj stoimosti rossijskimi kompanijami [Value creation determinants of Russian companies]. EJournal of Corporate Finance, vol. 29, no. 1, pp. 33-49.

4. Bebczuk R. (2005) Corporate governance and ownership: measurement and impact on corporate performance and dividend policies in Argentina. Center for Financial Stability working paper.

5. Bliss B.A., Cheng Y. and Denis D.J. 2014. Corporate payout, cash retention, and the supply of credit: Evidence from the 2008-2009 credit crisis. Journal of Financial Economics, vol. 115, no. 3, pp. 521-540.

6. Boubakri N. and Cosset J. C., 1998. The financial and operating performance of newly privatized firms: evidence from developing countries. The Journal of Finance, vol. 53, no. 3, pp. 1081-1110.

7. Brav A., Graham J.R., Harvey C.R. and Michaely R. (2005) Payout policy in the 21 st century. Journal of Financial Economics, vol. 77, no. 3, pp. 483-527.

8. Cornett M.M., Guo, L., Khaksari S. and Tehranian H. (2010) The impact of state ownership on performance differences in privately-owned versus state-owned banks: an international comparison. Journal of Financial Intermediation, vol. 19, no. 1, pp. 74-94.

9. Daniel N.D., Denis D. and Naveen L. (2008) Sources of financial flexibility: Evidence from cash flow shortfalls. Working Paper, Drexel University, Purdue University and Temple University.

10. Deshmukh S. (2003) Dividend initiations and asymmetric information: a hazard model. Financial Review, vol. 38, no. 3, pp. 351-368.

11. Dittmar A., Mahrt-Smith J. and Servaes H. (2003) International corporate governance and corporate cash holdings. Journal of Financial and Quantitative Analysis, vol. 38, no. 1, pp. 111-133.

12. D'souza J. and Megginson W.L. (1999) The financial and operating performance of privatized firms during the 1990s. The Journal of Finance, vol. 54, no. 4, pp. 1397-1438. 
13. Faccio M., Lang L.H. and Young L. (2001) Dividends and expropriation. American Economic Review, vol. 91, no. 1, pp. 54-78.

14. Fama E.F. and French K.R. (2001) Disappearing dividends: changing firm characteristics or lower propensity to pay? Journal of Financial Economics, vol. 60, no. 1, pp. 3-43.

15. Ferris S.P., Sen N. and Yui, H.P. (2006) God save the Queen and her dividends: corporate payouts in the United Kingdom. The Journal of Business, vol. 79, no. 3, pp. 1149-1173.

16. Floyd E., Li N. and Skinner D.J. (2014) Payout policy through the financial crisis: the growth of repurchases and the resilience of dividends. Chicago Booth Research Paper 12-01.

17. Ivashkovskaja I.V. and Kukina E.B. (2009) Determinanty jekonomicheskoj pribyli krupnyh rossijskih kompanij [Economic profit determinants of large-scale Russian companies]. EJournal of Corporate Finance, vol. 12, no. 4, pp. 18-33.

18. Keri I.T., Gromova E.I. and Sinel'shhikova N.V. (2013) Osobennosti dividendnyh vyplat $\mathrm{v}$ rossijskih kompanijah [Specific features of dividend payments of Russian companies]. Modern Trends in Economics and Management, no. 20, pp. 173-179.

19. Khan T. (2006) Company dividends and ownership structure: evidence from UK panel data. The Economic Journal, vol. 116, no. 510, pp. 172-189.

20. Kowalewski O., Stetsyuk I. and Talavera O. (2008) Does corporate governance determine dividend payouts in Poland? Post-Communist Economies, vol. 20, no. 2, pp. 203-218.

21. La Porta R., Lopez-de-Silanes F., Shleifer A. and Vishny R. (2000) Agency problems and dividend policies around the world. The Journal of Finance, vol. 55, no. 1, pp. 1-33.

22. Leary M.T. and Michaely R. (2011) Determinants of dividend smoothing: Empirical evidence. Review of Financial Studies, vol. 24, no. 10, pp. 3197-3249.

23. Lebedev O.V. (2015) Formirovanie akcionernoj stoimosti na nesovershennom rynke kapitala [Shareholder value creation in an inefficient capital market. Cand. econ. sci. diss.]. Kazan, 191 p.

24. Mian A. and Suf A. (2010) The great recession: Lessons from microeconomic data. The American Economic Review, vol. 100, no. 2, pp. 51-56.

25. Pirogov N.K. and Volkova N.N. (2014) Dividendnaja politika kompanij na razvivajushhihsja rynkah [Dividend policy: Evidence from emerging markets]. EJournal of Corporate Finance, vol. 12 , no. 4 , pp. 57 and 78.

26. Ruzhanskaja L. and Luk'janov S. (2012) Osobennosti dividendnoj politiki rossijskih kompanij i interesy investorov [Dividend policy of Russian companies and investors' interests]. Voprosy Ekonomiki, no. 3, pp. 132-146.

27. Sawicki J. (2009) Corporate governance and dividend policy in Southeast Asia pre-and postcrisis. The European Journal of Finance, vol. 15, no. 2, pp. 211-230.

28. Shagaleeva G.B. (2011) Osobennosti dividendnoj politiki kompanij razvivajushhihsja rynkov kapitala [Specific features of dividend policies of companies in emerging capital markets Cand. econ. sci. diss.]. Moscow, 181 p.

29. Shleifer A. and Vishny R.W. (1997) A survey of corporate governance. The Journal of Finance, vol. 52, no. 2, pp. 737-783.

30. StataCorp (2009) Stata longitudinal data reference manual: release 11.0. Stata Corporation Press, College Station, Texas.

31. Teplova T.V. (2008) Vlijanie dividendnyh vyplat na rynochnuju ocenku rossijskih kompanij: jempiricheskoe issledovanie metodom sobytijnogo analiza na rossijskih i zarubezhnyh torgovyh ploshhadkah [Impact of cash dividend payments on Russian companies' market capitalization: Event study testing on Russians and world's stock exchange]. Audit and Financial Analysis, no. 2, pp. 1-15.

32. Teplova T.V.(2011) Reakcija cen akcij na objavlenija denezhnyh dividendov: signalizirovanie na rossijskom rynke do i posle krizisa [Reaction on cash divided announcements: Signaling 
in the Russian market before and after crisis]. Financial Management, no. 1, pp. 13-25.

33. Zal'cman A.A. (2014) Osobennosti dividendnoj politiki rossijskih kompanij s kross-listingom [Dividend policy of cross-listed Russian companies]. Financial Research, vol. 45, no. 4, pp. 207-221.

\title{
CORPORATE GOVERNANCE AND EFFECTIVENESS OF A DIVERSIFIED COMPANY: RUSSIAN EXPERIENCE
}

\author{
Varvara Nazarova, \\ PhD in Economics, Researcher, Associate Professor, \\ National Research University Higher School of Economics, Russia \\ e-mailnvarvara@list.ru \\ Anzhelika Kolkina, \\ National Research University Higher School of Economics, Russia \\ e-mail lika.kolkina@yandex.ru
}

\begin{abstract}
Researchers come to controversial conclusions regarding the impact of corporate diversification on the company>s value and performance. The diversification strategy itself has been subject to strong criticism in the past 20-30 years. There is an opinion, however, that in emerging markets diversification has a positive impact on companies> value and effectiveness. Despite the existing advantages of diversified companies, planning and budgeting various business areas not related to each other is a considerably difficult task that results in the agency problem between managers and stakeholders. This leads to corporate governance problems in companies that use the diversification strategy.
\end{abstract}

Studying corporate governance in emerging countries is especially important, as they need to adjust their corporate governance standards to developed markets. The theory of corporate governance is now developing rapidly, especially in Russia, where researchers did not often turn to this subject. In the last decade, this issue has most often become a subject of research in China and India.

The issue of corporate governance in Russia is relevant today due to the fact that it is a mechanism of managing a company which makes it possible to balance the interests of managers and stakeholders. Moreover, companies are interested in attracting foreign investors, who pay significant attention to the level of current corporate governance. However, unlike in developed countries, corporate governance in developing capital markets is only being introduced. Today a lot of Russian companies are engaged in the optimisation of corporate governance largely to build a good reputation and do not pay enough attention to corporate governance principles, which a company should follow. Thus, today the low level of corporate governance is a problem in Russian companies, as the companies owners do not understand its significance. Moreover, the Russian business environment is rather specific and requires a certain approach in order to form an optimal corporate governance system. As far as research in this field is concerned, a positive impact of corporate governance on companies > effectiveness lacks empirical proof. A number of studies have not found a statistically significant positive correlation between the level of corporate governance in Russian companies and their effectiveness.

With regard to the stated issue, the purpose of this paper is to discover to what extent corporate governance has an impact on the effectiveness of Russian diversified companies. Such companies are a subject of particular interest, as not only developed and emerging economies have different features of corporate governance, but within one country there are also companies whose development strategy and industry have a significant impact on the optimal corporate governance structure. The study suggests the following hypothesis: the corporate governance system has a positive impact on the effectiveness of Russian diversified companies. 